\title{
Life history characteristics of Macrothrix rosea (Jurine, 1820) (Cladocera, Macrothricidae) in laboratory conditions
}

\author{
Xiaona $\mathrm{HUANG}^{1)}$ Xinlu SHI ${ }^{1,2)} *$ Sen $\mathrm{XU}^{3)}$ Guijie $\mathrm{LIU}^{1,2)}$ Limin $\mathrm{MA}^{1)}$ and Zhiqiang $\mathrm{SUN}^{1)}$ \\ ${ }^{1)}$ Hangzhou Key Laboratory for Animal Adaptation and Evolution, Hangzhou Normal University, Hang Zhou 310036, China. \\ ${ }^{2)}$ State Key Laboratory of Freshwater Ecology and Biotechnology, Institute of Hydrobiology, Chinese Academy of Sciences Wuhan \\ 430072, China. \\ ${ }^{3)}$ Great Lakes Institute for Environmental Research, University of Windsor, Windsor, Ontario, Canada, N9B 3P4 \\ *e-mail corresponding author: shix156@163.com
}

\section{ABSTRACT}

Our knowledge of the life history characters of medium-size cladoceran species remains quite restricted. In order to address this issue, the present study examined the life history of a medium-size species, Macrothrix rosea (Cladocera, Macrothricidae), in laboratory conditions. Neonates produced by previously acclimatized parthenogenetic females were cultured at $25 \pm 1{ }^{\circ} \mathrm{C}$ to investigate their growth rate, fecundity, and development. Our results show that individuals of M. rosea underwent three juvenile instar stages and 10 adult instars at $25^{\circ} \mathrm{C}$, with an average life span $33 \pm 6.33$ days. The average total number of eggs produced per individual was 121.04, with a maximum of 151. Individuals in the seventh instar stage (fourth adult instar) produced the largest number of offspring. The growth of body length showed a logarithmic pattern, whereas the cumulative fecundity and population growth appeared to be logistic. Furthermore, we compared the growth and mean fecundity from the birth to the first adult instar at three different temperatures (i.e., 15, 20, and $25{ }^{\circ} \mathrm{C}$ ). The growth rate of body length was slower at lower temperatures than at higher temperatures, while the mean fecundity was higher and the time needed for developing to adult was longer at lower temperatures. In conjunction with previous studies, our data suggest several shared life history characteristics among cladocerans.

Key words: Cladocera, morphology, growth, reproduction, instar

\section{INTRODUCTION}

Life history traits of cladocerans, such as growth rate of body length and reproduction, under different environmental conditions are indicative of the ecological fitness of a species, thus providing an insight into its distribution pattern in particular environments (Güntzel et al. 2003). Reproduction data also form an important parameter in the Monopolization Hypothesis that suggests a large amount of resting eggs is critical for maintaining the dominance of local populations and resisting the establishment of new colonizers (de Meester 1996). Empirical reproduction data under different environmental conditions are therefore valuable for detailed characterization of this hypothesis in different groups of freshwater zooplankton. Furthermore, to understand the evolution of life history traits of cladocerans, empirical data from species with different body sizes and ecological requirements are needed (Lynch 1980).

To date, life history traits such as growth rate of body length, reproduction, and development of individuals have been investigated predominantly in largesize cladoceran species, such as Daphnia pulex (Asaeda \& Acharya 2000), D. magna (Giebelhausen \& Lampert 2001), D. hyalina (Huang 1984), D. carinata (Huang 1984), D. longispina (Verbitskii et al. 2009), Simocephalus himalayensis microdus (Shi et al. 1996, 1997), Simocephalus himalayensis (Shi et al. 2010) and Diaphanosoma brachyurum (Verbitskii et al. 2009). By contrast, far fewer studies have focused on medium-size species (but see Murugan 1975; Lynch 1980; Benider et al. 2002; Urabe \& Watanabe 1990). As a result, the ecological and life history differences between large and medium-size cladoceran species remain poorly understood.

In order to address this issue, this study examines the life cycle of a medium-size cladoceran, Macrothrix rosea (Cladocera, Macrothricidae). M. rosea is a cosmopolitan species and is often found in ponds or lakes that are rich in organic matter. Hitherto, no data about the growth and reproduction of this species are available, although Güntzel et al. (2003) studied the life cycle of the closely related species Macrothrix flabelligera Smirnov, 1992. In this study, we present life history data concerning the post-embryonic development, growth of body length, fecundity, and population growth of $M$. rosea in laboratory conditions. Although the morphology of $M$. rosea from China has been previously described (Chiang \& Du 1979), we aim to provide improved data, including high-quality photographs, in order to aid its identification and to facilitate future comparative morphological analyses of geographically separated populations.

\section{MATERIAL AND METHODS}

Individuals of Macrothrix rosea were collected from a permanent pond in Yuhang of Hangzhou, Zhejiang Province, China (N30²5.161', E120 $\left.{ }^{\circ} 05.666^{\prime}\right)$. At the time of sampling, the pond was about $300 \mathrm{~m}^{2}$ and the 
Tab. 1. The mean body length (BL, mm), the mean development time ( $\mathrm{T}$, days), average egg production per individual (P), minimum and maximum egg production per individual (MP), average number of surviving individuals (AN) and survival rate of each instar (R) during each instar stages of Macrothrix rosea at $25^{\circ} \mathrm{C}$.

\begin{tabular}{ccccccc}
\hline Instar & $\mathrm{BL}( \pm \mathrm{SD})$ & $\mathrm{T}( \pm \mathrm{SD})$ & $\mathrm{P}( \pm \mathrm{SD})$ & $\mathrm{MP}$ & $\mathrm{AN}$ & $\mathrm{R}(\%)$ \\
\hline 1 & $0.299 \pm 0.001$ & $1.00 \pm 0.00$ & 0 & $0 / 0$ & 0 & 100 \\
2 & $0.415 \pm 0.005$ & $1.00 \pm 0.00$ & 0 & $0 / 0$ & 0 & 100 \\
3 & $0.532 \pm 0.014$ & $2.06 \pm 0.14$ & 0 & $0 / 0$ & 0 & 100 \\
4 & $0.664 \pm 0.016$ & $2.69 \pm 0.28$ & $4.13 \pm 0.20$ & $4 / 6$ & 4.13 & 100 \\
5 & $0.753 \pm 0.010$ & $2.88 \pm 0.31$ & $10.25 \pm 0.55$ & $7 / 14$ & 16.5 & 100 \\
6 & $0.812 \pm 0.011$ & $3.00 \pm 0.29$ & $16.75 \pm 0.54$ & $12 / 18$ & 32.25 & 100 \\
7 & $0.873 \pm 0.016$ & $3.13 \pm 0.27$ & $21.19 \pm 0.25$ & $16 / 22$ & 54.30 & 100 \\
8 & $0.901 \pm 0.015$ & $3.00 \pm 0.27$ & $20.31 \pm 0.59$ & $18 / 22$ & 76.26 & 100 \\
9 & $0.919 \pm 0.014$ & $3.00 \pm 0.27$ & $17.13 \pm 0.82$ & $18 / 21$ & 98.39 & 99.35 \\
10 & $0.934 \pm 0.011$ & $3.06 \pm 0.26$ & $13.25 \pm 0.78$ & $12 / 16$ & 114.83 & 85.00 \\
11 & $0.942 \pm 0.011$ & $3.19 \pm 0.24$ & $9.19 \pm 0.96$ & $8 / 14$ & 138.23 & 64.66 \\
12 & $0.944 \pm 0.013$ & $3.23 \pm 0.26$ & $5.44 \pm 0.96$ & $5 / 10$ & 146.25 & 39.94 \\
13 & $0.966 \pm 0.012$ & $3.44 \pm 0.49$ & $3.4 \pm 1.08$ & $1 / 8$ & 151.07 & 14.97 \\
Total & & 37.68 & 121.04 & $101 / 151$ & & \\
\hline
\end{tabular}

depth was about $2 \mathrm{~m}$. The water temperature was 24.5 ${ }^{\circ} \mathrm{C}$, the $\mathrm{pH}$ was 7.6 , the biochemical oxygen demand (BOD5) was $1.4 \%$, the dissolved oxygen (DO) concentration was $95.6 \%$, the total phosphorous (TP) concentration was $2.24 \mathrm{mg} \mathrm{L}^{-1}$, and the total nitrogen $(\mathrm{TN})$ concentration was $4.21 \mathrm{mg} \mathrm{L}^{-1}$.

Live zooplankton samples were collected using a plankton net with a mesh size of $64 \mu \mathrm{m}$ and then brought to the laboratory where individuals of Macrothrix rosea were isolated. Individuals were kept in $10 \mathrm{~mL}$ containers with filtered pond water from the same location under a light/dark regime of 12/12 h and 1800-2000 lx illuminance. In total, 16 clones were maintained at 25.0 $\pm 1{ }^{\circ} \mathrm{C}$, and 10 clones were cultured to the first adult instar at $15{ }^{\circ} \mathrm{C}$ and $20^{\circ} \mathrm{C}$, respectively. We define the first instar at birth, and after each molting a new instar stage is entered. The first adult instar is entered when females carry their first eggs.

Neonates less than four hour old were isolated and individually maintained in $10 \mathrm{~mL}$ containers. They were fed with an algal suspension of Scenedesmus bijugus at a concentration of $25-30 \times 10^{5}$ cells $\mathrm{mL}^{-1}$. Half of the lake water was changed with filtered lake water every other day. Neonates were examined four times (6:00 am, 12:00 am, 18:00 pm, 22:00 pm) everyday. Instars were measured according to exuviations, and their body lengths were measured with ocular micrometer after each molting. After individuals became sexually mature, the number of eggs and the number of offspring produced were recorded, and the survival rate of each instar was calculated as the average number of surviving individuals divided by the average eggs production (Tab. 1). The offspring was immediately removed in order to ensure an optimal environment for the mothers. For each instar stage, an index of survival rate $\left(L_{x}\right)$ was calculated as the average number of surviving individuals divided by the average number of eggs produced. Also, we calculated the birth rate $\left(m_{x}\right)$ for 13 age groups (each consisting of 3 days) as the average number of offspring per day. The net reproduction rate for each age group was defineded as $L_{x} m_{x}$, and the net reproductive rate $R_{0}$ as $\sum L_{x} m_{x}$ (Tab. 2).

Following the methods of Liang and Zhang (1964), the intrinsic rate of natural increase was calculated as $r_{m}$ (/day) $=\ln R_{0} / T$, the population increase double times as $t(/$ day $)=(\operatorname{Ln} 2) / r_{m}$, the finite rate of increase as $\lambda$ (/day) $=\mathrm{e}^{r m}$, and the instantaneous rate of increase as $r=\ln$ $\left(N_{t} / N_{0}\right) / t$, where $N_{t}$ equals $N_{0} \mathrm{e}^{r t}\left(N_{t}:\right.$ total number of individuals, $N_{0}$ : initial value of the population size).

We used SigmaPlot 10.0 to perform curve fitting for all the distribution obtained in data analyses. Body length measurements were plotted against time (Fig. 1). The increment of body length $\left(Y_{l}\right)$ and the rate of increment of body length growth $\left(Y_{r}\right)$ are defined as $Y_{l}=$ $L_{2}-L_{1}$, and $Y_{r}=100 \% \times\left(L_{2}-L_{1}\right) / L_{1}$, respectively. A body length increment instar relationship was estimated (Fig. 2). The relationship between the mean fecundity, defined as the number of eggs per female in each instar, and instar stages was examined (Fig. 3). We also investigated the relationship between the maximum cumulative fecundity (i.e., the maximum eggs produced per individual, Tab. 1) and instar stage (Fig. 4).

\section{RESULTS}

\subsection{Growth}

The life span of individuals was 33 to 37 days ( $\mathrm{n}=$ 16) (Tab. 1). The mean body length ranged from 0.299 $\pm 0.001 \mathrm{~mm}$ in newborns to $0.966 \pm 0.012 \mathrm{~mm}$ at death (Tab. 1). Adults reached a maximal length of $1.04 \mathrm{~mm}$. The change of body size during the entire life span of individuals is shown in figure 1. The correlation between time (days) and body length $\left(L_{t}\right)$ is best described as the von Bertalanffy equation: $L_{t}=1.04$ (1 $\left.\mathrm{e}^{-0.1455(\mathrm{t}+1.3625)}\right)\left(\mathrm{R}^{2}=0.97\right)$.

The growth of body length for Macrothrix rosea was not continuous. The increase of body length is accompanied by entering a new instar stage. There were three larval instars and ten mature instars during the life cycle of $M$. rosea at $25{ }^{\circ} \mathrm{C}$. Individuals of Macrothrix rosea 
grew rapidly when they were young. In the first week of their life, the increase of body length was rapid. The mean body length at the first instar was $0.299 \pm 0.001$ $\mathrm{mm}$ and reached $0.415 \pm 0.005 \mathrm{~mm}$ at the second instar, with a growth rate of $38.9 \%$. Between the second and the third instars, and the third and the fourth instars, the rate of growth was $28.2 \%$ and $24.8 \%$, respectively.

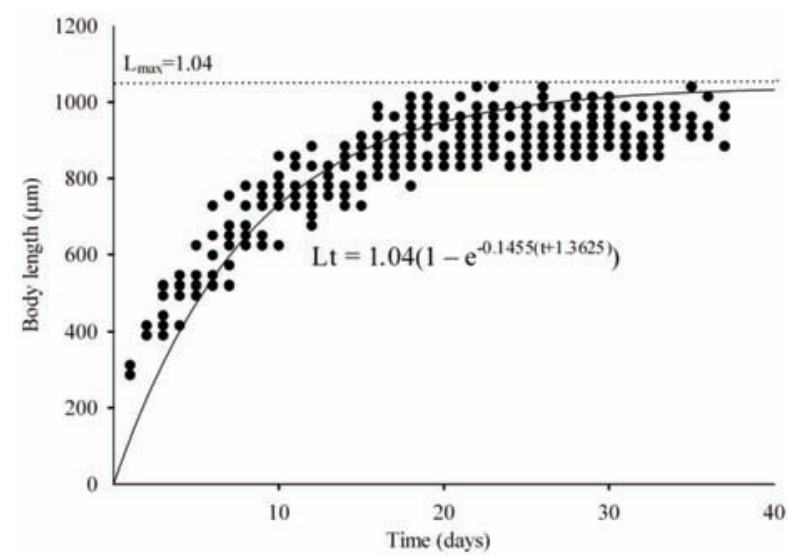

Fig. 1. The correlation between time (t) and body length (Lt) of Macrothrix rosea cultured at $25^{\circ} \mathrm{C}$. The data points represent the mean body lengths of 16 individuals at each day of the life cycle.

The body length increase showed a rising trend during the first three instars and then started to decrease until death (Fig. 2), whereas the rate of growth continuously decreased, with the first five instars showing the highest rate. It is therefore clear that body length of individuals grow much faster when they are young compared to later stages. Furthermore, the development time of young individuals is shorter than most mature individuals. The mean development time for the first three instars was $1.00 \pm 0.00$ days, $1.00 \pm 0.00$ days and $2.06 \pm 0.14$ days, respectively (Tab. 1 ). All subsequent instar stages required more than two and a half days. Notably, the development time in the last instar stage was about three and a half days, and the total development time was 37.68 days (Tab. 1 and Fig. 1).

\subsection{Reproduction}

Parthenogenetic individuals reached sexual maturity at the third instar when individuals started carrying broods and began to reproduce in the next instar. During their life cycle, each individual produced ten broods on average. The relationship between instars and the mean fecundity at $25{ }^{\circ} \mathrm{C}$ is shown in figure 3 . The number of offspring increases with the advancement of instar stages. In the first adult instar ( $4^{\text {th }}$ instar), the average number of offspring was four, and the highest number of offspring (i.e., 22) was observed in instars 6-8 (i.e., $3^{\text {rd }}-5^{\text {th }}$ adult instars). Then, the number of offspring started to decline until individuals died, with the mean fecundity being $3.4 \pm 1.08$ in the last instar.

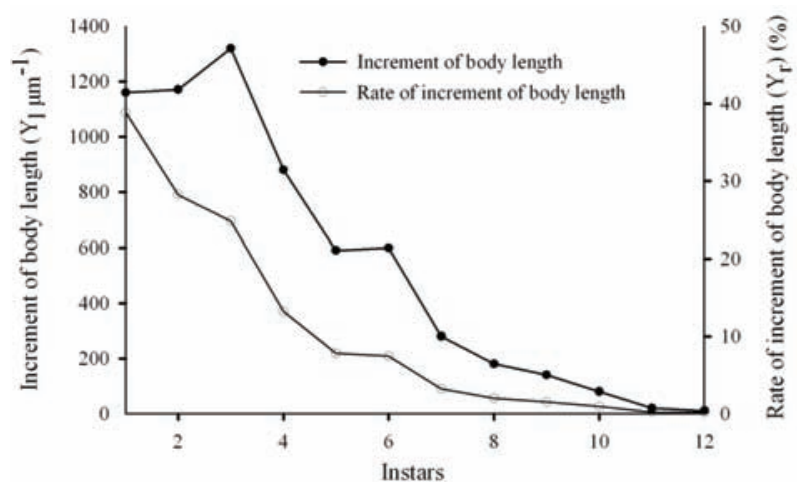

Fig. 2. The overall trend of the increase of body length and the rate of increment of body length during the entire life span of $M$. rosea individuals at $25{ }^{\circ} \mathrm{C}$. The left vertical axis denotes the increment of body length, while the right one designates the rate of increment of body length. The increase of body length is defined as such: $\mathrm{Y}_{1}=\mathrm{L}_{2}-\mathrm{L}_{1}$, and $\mathrm{Y}_{\mathrm{r}}=100 \% \times\left(\mathrm{L}_{2}--\right.$ $\left.L_{1}\right) / L_{1}$, where $Y_{1}$ denotes the increment of body length, $Y_{r}$ denotes the rate of increment of body length, $L_{1}$ denotes body length at the previous instars, and $\mathrm{L}_{2}$ denotes body length at the next instars.

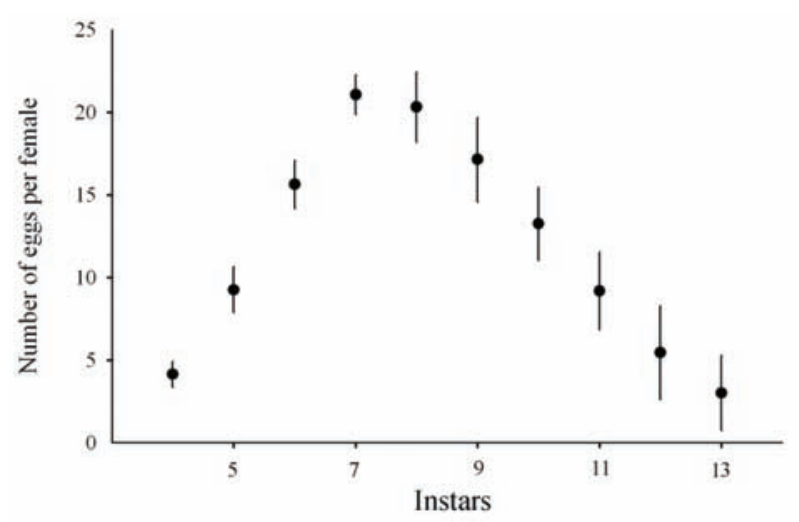

Fig. 3. The relationship between instar stages and the mean fecundity per individual of Macrothrix rosea at $25^{\circ} \mathrm{C}$.

The mean total brood was 121.04 per individual during its life cycle (Tab. 1). The survival rate of offspring was estimated to be almost $100 \%$, except in the last three instars. In the last instar stage, the survival rate was just $14.97 \%$, because many eggs were degraded. The relationship between instar stages and the maximum cumulative fecundity was best described as a Sigmoidal curve growth model (Fig. 4), i.e., $F=151 /(1+$ $\left.\mathrm{e}^{5.189-0.667 \mathrm{x}}\right)\left(\mathrm{R}^{2}=0.99\right)$, where $F$ represents the maximum cumulative fecundity and $x$ denotes instars.

\subsection{Life history characters}

Based on the survival and birth rate data (Tab. 2), we obtained values of the following parameters: $R_{0}=$ 113.22/generation, $T$ (days) $=6.75, r_{m}(/$ day $)=0.70$, and $t$ (/day) $=0.99$. Consequently, the increase from a female per day was 0.70 and the population size doubles in 0.99 days. 


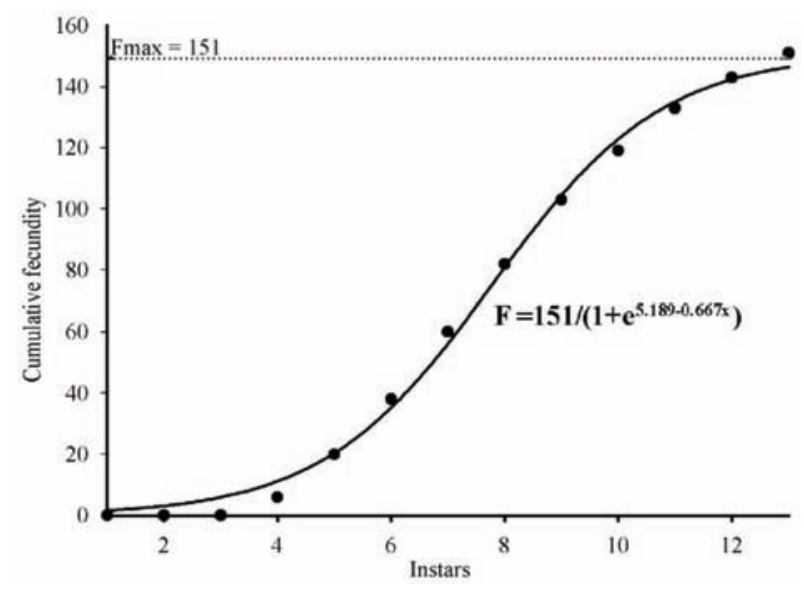

Fig. 4. The relationship between instar stages and the maximum cumulative fecundity per individual at $25^{\circ} \mathrm{C}$. The data points represent the maximum cumulative fecundity.
2465, and the population growth of $M$. rosea is best described with a logistic growth model (Fig. 5), where y $=2465 /\left(1-\mathrm{e}^{3.6815-0.3426 t}\right)\left(\mathrm{R}^{2}=0.99\right)$, with $\mathrm{y}$ denoting the population size and $t$ representing time (days).

\subsection{Fecundity in the first adult instar at different temperatures}

The fecundity of individuals in the first mature instar decreased as the temperature increased. The number of eggs was $5.00 \pm 0.54$ at $15^{\circ} \mathrm{C}, 4.40 \pm 0.57$ at $20^{\circ} \mathrm{C}$, and $4.25 \pm 0.19$ at $25{ }^{\circ} \mathrm{C}$. At the three temperatures, the maximum fecundity was 10 (at $20^{\circ} \mathrm{C}$ ), and the minimum was one (at $15^{\circ} \mathrm{C}$ ).

Temperature not only influenced fecundity but also the number of larval instars, the growth of body length, and time required to become sexually mature. The number of larval instars was 4 at $15^{\circ} \mathrm{C}$, 3 at $20^{\circ} \mathrm{C}$ and 3 at

Tab. 2. Life and fecundity tables of Macrothrix rosea at $25^{\circ} \mathrm{C}$.

\begin{tabular}{ccccc}
\hline $\begin{array}{c}\text { Age group } \\
\text { (days) }\end{array}$ & $\begin{array}{c}\text { Median of age } \\
\text { (days) }\end{array}$ & $\begin{array}{c}\text { Survival rate } \\
\left(\mathrm{L}_{\mathrm{x}}\right)\end{array}$ & $\begin{array}{c}\text { Birth rate } \\
\left(\mathrm{m}_{\mathrm{x}}\right)\end{array}$ & $\begin{array}{c}\text { Net reproduction rate } \\
\left(\mathrm{L}_{\mathrm{x}} \mathrm{m}_{\mathrm{x}}\right)\end{array}$ \\
\hline $0-2$ & 1 & 1 & 0 & 0 \\
$3-5$ & 4 & 1 & 0 & 0 \\
$6-8$ & 7 & 1 & 4.13 & 4.13 \\
$9-11$ & 10 & 1 & 10 & 10 \\
$12-14$ & 13 & 1 & 16.75 & 16.75 \\
$15-17$ & 16 & 1 & 21.19 & 21.19 \\
$18-20$ & 19 & 1 & 19.19 & 19.19 \\
$21-23$ & 22 & 1 & 16 & 16 \\
$24-26$ & 25 & 1 & 12.13 & 12.13 \\
$27-29$ & 28 & 1 & 7.44 & 7.44 \\
$30-32$ & 31 & 0.875 & 5 & 4.38 \\
$33-35$ & 34 & 0.5 & 3.4 & 1.7 \\
$36-39$ & 37 & 0.3125 & 1 & 0.31 \\
Total & & & & 113.22 \\
\hline
\end{tabular}

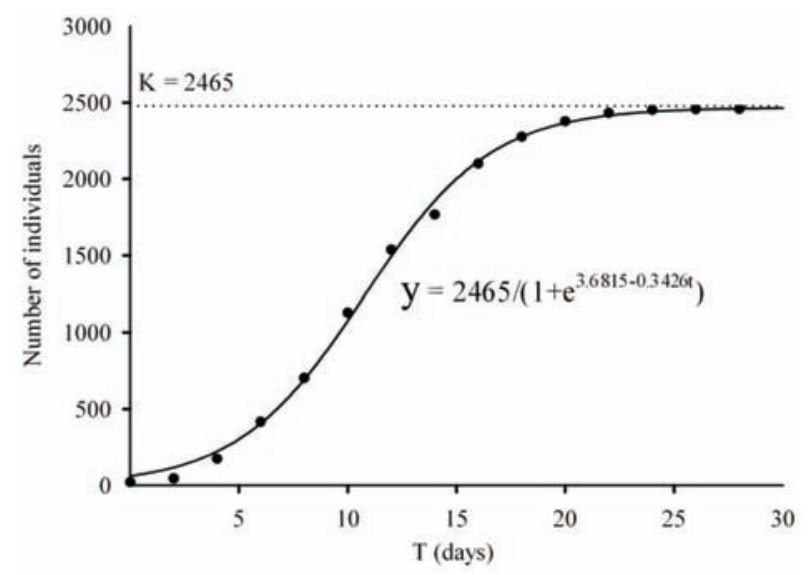

Fig. 5. The logistic growth curve showing the cumulative production for 20 individuals of Macrothrix rosea in 30 days at $25^{\circ} \mathrm{C}$.

The finite rate of increase $\lambda$ (/day) $=2.02$, i.e., the expected rate of increase of population size $(\lambda)$ was 2.02 times per day. According to the growth parameters given above, when $N_{0}=20$, the carrying capacity $(K)$ equals
$25{ }^{\circ} \mathrm{C}$ (Tab. 3). When individuals became sexually mature, the body length was $0.70 \pm 0.26 \mathrm{~mm}$ at $15^{\circ} \mathrm{C}$, $0.68 \pm 0.16 \mathrm{~mm}$ at $20^{\circ} \mathrm{C}$, and $0.66 \pm 0.01 \mathrm{~mm}$ at $25^{\circ} \mathrm{C}$. The time needed to reach sexual maturity was $7.62 \pm$ 0.53 days at $15{ }^{\circ} \mathrm{C}, 5.26 \pm 0.14$ days at $20^{\circ} \mathrm{C}$, and 4.06 \pm 0.33 days at $25^{\circ} \mathrm{C}$.

Tab. 3. Time (T) and instars needed for reaching sexual maturity at different temperatures and the effect of temperature on the body length (BL) and mean fecundity (F).

\begin{tabular}{c|cccc}
\hline Temperature & Instars & $\mathrm{BL}( \pm \mathrm{SE})$ & $\mathrm{F}( \pm \mathrm{SE})$ & $\mathrm{T}$ (days) \\
\hline \multirow{3}{*}{$15{ }^{\circ} \mathrm{C}$} & 1 & $0.31 \pm 0.08$ & & \\
& 2 & $0.39 \pm 0.00$ & & \\
& 3 & $0.48 \pm 0.20$ & & $7.62 \pm 0.53$ \\
& 4 & $0.58 \pm 0.18$ & & \\
$20{ }^{\circ} \mathrm{C}$ & 5 & $0.70 \pm 0.26$ & $5.00 \pm 0.54$ & \\
& 1 & $0.31 \pm 0.29$ & & \\
& 2 & $0.41 \pm 0.20$ & & \\
& 3 & $0.56 \pm 0.24$ & & $5.26 \pm 0.14$ \\
$25{ }^{\circ} \mathrm{C}$ & 4 & $0.68 \pm 0.16$ & $4.40 \pm 0.57$ & \\
& 1 & $0.30 \pm 0.00$ & & \\
& 2 & $0.42 \pm 0.00$ & & \\
& 3 & $0.53 \pm 0.00$ & & $4.06 \pm 0.33$ \\
& 4 & $0.66 \pm 0.01$ & $4.25 \pm 0.19$ & \\
\hline
\end{tabular}




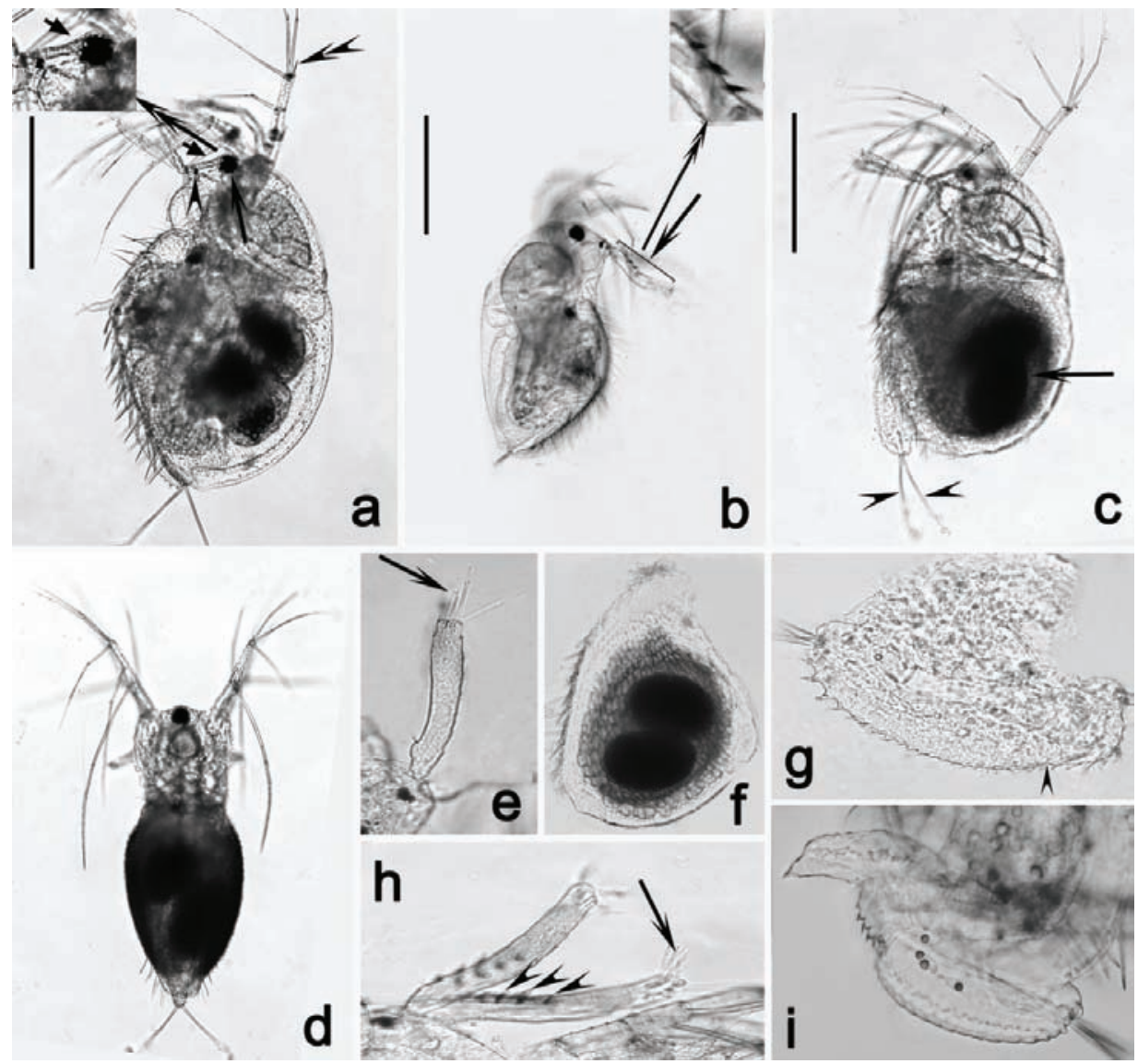

Fig. 6. Photographs of live individuals of Macrothrix rosea. (a) Overview of the parthenogenetic females with parthenogenetic eggs in the brood chamber. Arrows indicate the compound eye, the ocellus, the protrude on the head, respectively. The double-arrow head designates the spine on each section of the second antennae (0-0-1-3/1-1-3), and the double-arrow points to the enlargement of the sharp turn (i.e. protrude) at the back of head between the compound eyes; (b) Overview of the male, with the arrow showing the first antennae, and the double-arrow showing the enlargement of groups of strong setules on the first antennae; (c) Overview of the female with two sexual eggs in epphipa (arrow). The sensory setae are also indicated by arrow heads; (d) Dorsal view of the parthenogenetic females; (e) The first antennae of female and its sensory hairs (arrow); (f) ephippium with two sexual eggs; (g) Postabdomen of female, showing the abdominal processes, postabdominal claw, anal bay, anal spines, and the bilobed dorsal margin (arrow head); (h) The first antennae of male, with the arrow heads showing the four groups of strong setules in lateral orientation and nine sensory hairs at the terminal; (i) Postabdomen of male, showing the abdominal processes and its tapering tubular ending. Scale bar denotes $500 \mu \mathrm{m}$ for a and c; $200 \mu \mathrm{m}$ for b.

\subsection{Morphology}

Female. The body is oval in shape with the dorsal valve margin curved from the tip of the rostrum, and the posterior dorsal corner straight. The ventral valve margin is serrated. The compound eyes are located close to the margin and are about equally distant from the vertex and the base of the first antennae (Fig. 6a). The ocellus is small and situated closer to the base of the first antennae than to the eyes (Figs 6a, 6b, 6c). The first antennae are long and thin (Fig. 6e). The first antennae show small indentations, and nine terminal sensory hairs of different length, and three of which are much longer than the others. The formula of the swimming setae of the second antennae is $0-0-1-3 / 1-1-3$, and that of the spines $0-1-0-1 / 0-0-1$ (Figs 6a, 6b, 6c, 6d). The size of winter eggs can reach about $1 / 3$ of the body length. Winter eggs are oval-shaped, with the surface of the ephippium consisting of many hexagons (Fig. 6f). The postabdomen is short and thick (Fig. 6g). The ventral margin is smooth and the dorsal margin clearly bilobed. The preanal zone has about 20 anal spines, and postanal zone has some spinous setae (Fig. 6g). The terminal claw is short, smooth, and evenly curved. The sensory setae are long with a relatively long proximal segment, a distal segment, and a few pinniform setules (Figs 6c, 6g).

Male. The body is oval in shape and about 0.37-0.42 $\mathrm{mm}$ long. The dorso-posterior valve angle with a conspicuously sharp (Fig. 6b). The first antennae are long, and each has a sensory papilla that is located ventro-laterally at the proximal segment and four groups of strong setules (Figs 6b, 6h). The nine terminal sensory hairs can be divided into two groups of different length, with three of them being much longer than the rest (Fig. 6h). The postabdominal region is characterized by a tubular ending that tapers at its apex, without true end-claws (Fig. 6i). 
Tab. 4. Some parameters on life history among different cladoceran species. The maximum body length (BL), instars (I), the mean lifespan (ML), and reproduction (R), at various temperatures (T).

\begin{tabular}{lcccccl}
\hline Species & BL $(\mathrm{mm})$ & $\mathrm{I}$ & $\mathrm{ML}$ (days) & $\mathrm{R}$ & $\mathrm{T}$ & Source \\
\hline Daphnia magna & 4.0 & 27 & 68.4 & 567 & $25^{\circ} \mathrm{C}$ & Zhuang \& Liang 1986 \\
Daphnia pulex & 2.91 & 24 & 65.5 & 401.6 & $25^{\circ} \mathrm{C}$ & Cao et al. 1996 \\
Daphnia cristata & 2.506 & 17 & 29.16 & N/A & $25^{\circ} \mathrm{C}$ & Huang 1984 \\
Daphnia hyalina & 2.52 & 20 & 35.2 & N/A & $25^{\circ} \mathrm{C}$ & Huang 1984 \\
Simocephalus himalayensis microdus & 3.35 & 20 & 48.7 & 361 & $20^{\circ} \mathrm{C}$ & Shi \& Shi 1996 \\
Simocephalus himalayensis & 3.02 & 23 & 45.5 & 447 & $25^{\circ} \mathrm{C}$ & Shi et al. 2010 \\
Moina irrasa & 1.93 & 13 & 31 & 239 & $25^{\circ} \mathrm{C}$ & Shi et al. 2009 \\
Moina micrura & 1.08 & 11 & 19.1 & 101.21 & $25^{\circ} \mathrm{C}$ & Cao et al. 1998 \\
Macrothrix flabelligera & 1.07 & 12 & 12.7 & 122.3 & $25^{\circ} \mathrm{C}$ & Güntzel et al. 2003 \\
Macrothrix rosea & 1.04 & 13 & 33 & 121.9 & $25^{\circ} \mathrm{C}$ & This work
\end{tabular}

\section{DISCUSSION}

This work examines several life history characters including body length growth, number of instars, and fecundity of the medium-size cladoceran species Macrothrix rosea. In light of previous studies, our results suggest several shared life history characteristics and also differences between large and medium-size species.

In cladocerans, it appears that most of the energy and nutrition by the individuals is used for growth in juvenile instars, whereas a large amount of energy is allocated to reproduction in adult instars (Lynch 1980). This is why the speed of growth becomes slower and the number of eggs produced per individual becomes higher with age. The growth characteristic of $M$. rosea is similar to most cladocerans, with individuals growing most rapidly when they are young, i.e., during the larval stages, and slowing down after reaching sexual maturity. The rate of increase of body length is highest in the first three larval instars and becomes increasingly lower when individuals enter adult instars. This characteristic is consistent with the growth pattern of Daphnia magna (Giebelhausen \& Lampert 2001), D. pulex (Asaeda \& Acharya 2000), Simocephalus himalayensis microdus (Shi et al. 1996, 1997), and Moina macrocopa (Benider et al. 2002). When individuals are in the early stages of the life cycle (1-9 instars) and given the required conditions, e.g., appropriate temperature, sufficient food, and excellent water quality, the survival rate is high. In the 10-11 instars, the survival rate starts to drop rapidly, but still significantly higher than that for the last two instars, presumably because of the accelerated decline of individual fitness during the last two instars (Cao et al. 1996; Santos et al. 2006; Shi et al. 2009).

Similar to other cladocerans, the body length growth of Macrothrix rosea is not continuous. Our results show there were three larval instars and ten mature instars at $25^{\circ} \mathrm{C}$. The longevity of $M$. rosea reached about 33 days on average. Three juvenile instars and nine adult instars were reported in Macrothrix flabelligera (Güntzel et al. 2003). However, the mean longevity of the species $M$. rosea recorded in the present study at $25^{\circ} \mathrm{C}$ is longer than that of $\mathrm{M}$. flabelligera (13.6 days) at $23{ }^{\circ} \mathrm{C}$. It is likely the different species have the same number of juvenile instars but different longevity.
It seems that large-size species generally have more instar stages and longer lifespan than medium-size species. As shown in table 4, the body lengths of the largesize species Daphnia magna, D. pulex, Simocephalus himalayensis microdus, and S. himalayensis are about three times longer than the medium-size species Moina micrura, Macrothrix flabelligera and M. rosea. Correspondingly, the number of the instar stages and the life spans of the former three species are approximately twice or even more than those of the latter (Zhuang \& Liang 1986; Cao et al. 1996; Shi \& Shi 1996; Cao et al. 1998; Güntzel et al. 2003; Shi et al. 2010).

A general feature for the reproduction of cladocerans is that when the individuals enter post-adolescence, they reach maximum fecundity, whereas when they approach the last few instars (i.e., $11^{\text {th }}$ to $13^{\text {th }}$ instars), their fecundity begins to decline and some individuals even stop reproducing in the last two instars. Given appropriate conditions, e.g., sufficient food and suitable temperatures, adults of $M$. rosea reproduce in each subsequent instar until death. This phenomenon has also been reported for the large-size species Daphnia magna (Zhuang \& Liang 1986) and Simocephalus himalayensis (Shi et al. 2010), and for the medium-size species Moina irrasa (Shi et al. 2009).

It is generally believed that temperature is the most important factor in the growth of cladocerans (Giebelhausen \& Lampert 2001; Benider et al. 2002; Rinke \& Petzoldt 2003; Shi et al. 2009). Indeed, we found that in Macrothrix rosea the growth pattern is conspicuously different at different temperatures. The number of juvenile instar stages (4) at $15{ }^{\circ} \mathrm{C}$ is more than that at $20^{\circ} \mathrm{C}$ (3) and $25^{\circ} \mathrm{C}$ (3) (Tab. 3). It is likely that individuals need more developmental time (i.e., more larval instars) at lower temperature to reach a state suitable for reproduction. Furthermore, at the lower temperature $\left(15^{\circ} \mathrm{C}\right)$ the mean body length and the mean fecundity during adult stages were significantly lower compared to those at higher temperatures (i.e., $20^{\circ} \mathrm{C}$ and $25^{\circ} \mathrm{C}$ ) (Tab. 3). This is probably due to the slower metabolism at lower temperature. A similar pattern regarding growth and reproduction at $20^{\circ} \mathrm{C}$ and $25{ }^{\circ} \mathrm{C}$ suggests that they are within the optimal range of temperatures for individuals of $M$. rosea. 
We compared the morphological characteristics of the Yuhang population of $M$. rosea with the original description from Jurine (1820) and other authors (Chiang \& Du 1979). Most morphological characters of our isolates were identical with the previous description, the only significant difference being the larger female body size in the Yuhang population (0.532-1.04 mm vs $0.47-0.62 \mathrm{~mm}$ ), which could be due to phenotypic plasticity. Morphological characters that can be used to distinguish $M$. rosea from congeners include the protrusion on the head, a sharp turn at the back of head between the compound eyes (Fig. 6a), 7 of the small indentations on the first antennae (Fig. 6e), anal spines, and the bilobed dorsal margin (Fig. 6g). The number of anal spines on postabdominal claw is different from other species, and there are about 20 anal spines at preanal zone (Fig. 6g). The morphological characteristics of males (Fig. 6b) are consistent the description of Chiang \& Du (1979), with the postabdomen showing a tubular ending, which tapers at its apex, without true end-claws (Fig. 6i), and 4 groups of strong setules on the first antennae of males (the double-arrow in Fig. 6b).

\section{CONCLUSIONS}

This study shows that $M$. rosea shares several common life history characteristics with other cladoceran species. However, due to its medium-size body, its fecundity level and the number of instar stages are much less than large-size species. The detailed characterization of the life history characters of $M$. rosea will facilitate future comparative studies.

\section{ACKNOWLEDGEMENTS}

This work was partly supported by the National Natural Science Foundation of China (31071880, 31030059), Zhejiang Provincial Natural Science Foundation of China (Y3100128), National Key Laboratory of Freshwater Ecology and Biotechnology of China (2009FB11), and Hangzhou Key Laboratory for Animal Adaptation and Evolution (2010100333T05), Hangzhou Normal University. We would like to give heartfelt thanks to the Researcher, Dr. Alan Warren, Department of Zoology, Natural History Museum, London and Dr. Hongliang Wang, College of Life Sciences, Zhejiang University for their assistance and encouragement.

\section{REFERENCES}

Asaeda, T. \& K. Acharya. 2000. Application of individual growth and population models of Daphnia pulex to Daphnia magna, Daphnia galeata and Bosmina longirostris. Hydrobiologia, 421: 141-155.

Benider, A., A. Tifnouti \& R. Pourriot. 2002. Growth of Moina macrocopa (Straus 1820) (Crustacea,Cladocera): influence of trophic conditions, population density and temperature. Hydrobiologia, 468: 1-11.

Cao, S., G. Jin \& X. Zhao. 1996. Effect of temperature on the growth and reproduction of Daphnia pulex (de Geer). Sichuan Journal of Zoology, 15: 100-104.
Cao, S., X. Lin, C. Huang \& Y. Luo. 1998. Population growth and reproduction of Moina micrura KURZ. Chin. J. Appl. Environ. Biol., 4: 37-39.

Chiang, X. \& N. Du. 1979. Fauna Sinica, Crustacea, Freshwater Cladocera. Science Press, Academia Sinica, Beijing, China: 185-193 pp. (in Chinese).

De Meester, L. 1996. Local genetic differentiation and adaptation in freshwater zooplankton populations: Patterns and processes. Ecoscience, 3: 385-399.

Du, N. \& W. Lai. 1983. The growth and reproduction of Daphnia carinata King. Journal of East China Normal University (Natural Science), 1: 85-91.

Giebelhausen, B. \& W. Lampert. 2001. Temperature reaction norms of Daphnia magna: the effect of food concentration. Freshwat. Biol., 46: 281-289.

Güntzel, A.M., T. Matsumura-Tundisi \& O. Rocha. 2003. Life cycle of Macrothrix flabelligera Smirnov, 1992 (Cladocera, Macrothricidae), recently reported in the Neotropical region. Hydrobiologia, 490: 87-92.

Huang, X. 1984. Effect of temperature on development and growth of Daphnia hyalina and Daphnia carinata ssp. (Cladocera-daphnidae). Acta Hydrobiologica Sinica, 8: 207-223.

Jurine, L. 1820. Histoire des Monocles, qui se trouvent aux environs de Genève. Paris: 260 pp.

Liang, Y. \& G. Zhang. 1964. Innate capacity of increase of Daphnia carinata King. Acta Hydrobiologica Sinica, 5: 31-36.

Lynch, M. 1980. The evolution of cladoceran life histories. Quart. Rev. Biol., 55: 23-42.

Murugan, N. 1975. Egg production, development and growth in Moina micrura Kurz (1874) (Cladocera: Moinidae). Freshwat. Biol., 5: 245-250.

Rinke, K. \& T. Petzoldt. 2003. Modelling the effects of temperature and food on individual growth and reproduction of Daphnia and their consequences on the population level. Limnologica, 33: 293-304.

Santos, M., M.G.G. Melão \& A.T. Mombardi. 2006. Life history characteristics and production of Ceriodaphnia silvestrii Daday (Crustacea, Cladocera) under different experimental conditions. Acta Limnol. Bras., 18 (2): 199-212.

Shi, X. \& X. Shi. 1996. Reproduction and development of Simocephalus Himalayensis microdus (Crustacea: Cladocera). Acta Zoological Sinca, 42: 287-297.

Shi, X., L. Yu, D. Zhang \& X. Shi. 1997. Studies on the growth and model of population growth in Simocephalus himalayensis microdus. Oceanologia et Limnologia Sinica, 28: 262-270.

Shi, X., C. Qi, G. Liu, S. Bao \& X. Huang. 2010. The effects of temperature on the growth and reproduction in Simocephalus himalayensis. Acta Hydrobiologica Sinica, 34: 794-805.

Shi, X., S. Bao, G. Liu, C. Qi, M. Cui \& Z. Zhang. 2009. Effect of the temperature on the reproduction capacity of Moina irrasa. Acta Hydrobiologica Sinica., 33: 200-206.

Smirnov, N. 1992. The Macrothricidae of the world, 1. Guides to the identification of the Microinvertebrates of the continental waters of the world. SPB Academic Publishing, The Hague: 143pp.

Urabe, J. \& Y. Watanabe. 1990. Influence of food density on respiration rate of two crustacean plankters, Daphnia galeata and Bosmina longirostris. Oecologia, 82: 362-368.

Verbitskii, V.B., T.I. Verbitskaya \& O.A. Malysheva. 2009. Population Dynamics of Daphnia longispina (O.F. Müller, 1785) and Diaphanosoma brachyurum (Lievin, 1848) (Crustacea, Cladocera) under Stable and Graded Temperature Regimes. Ecology, 36: 66-73.

Zhuang, D. \& Y. Liang. 1986. Studies on the growth, reproduction and model of population growth of Daphnia magna Straus. Acta Hydrobiologica Sinica, 10: 24-31.

Received: April 2011

Accepted: May 2011 